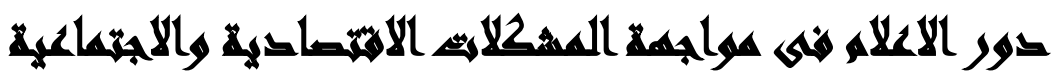 بهماهظكلة شمال سيخناك
}

[ir]

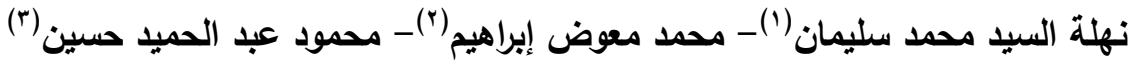

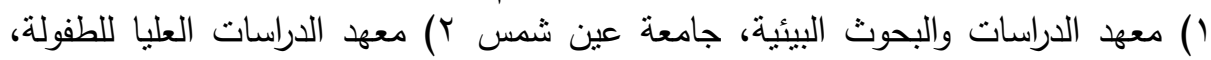
جامعة عين شمس r) كلية الآداب، جامعة دمياط

\section{المستخلس}

استهرف هذا البحث التعرف على أهمية مصادر معلومات المبحوثين بمنطقة الدراسة، وأيضا

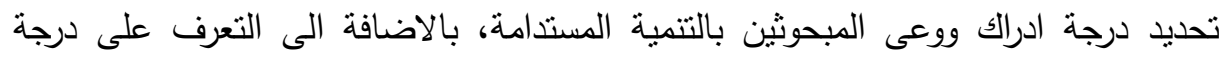

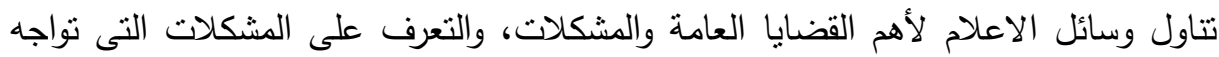

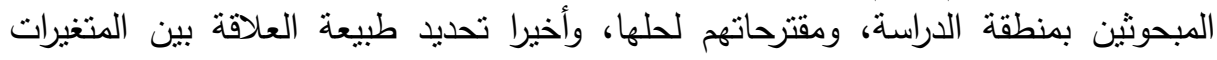
المستقلة المدروسة وبين درجة ادراك ووعى المدئ المبحوثين بالتتمية المستدامة.

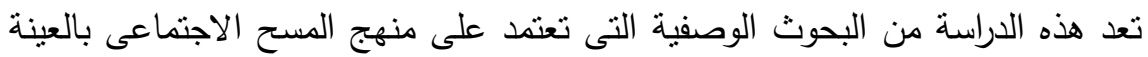

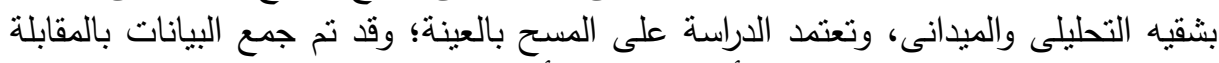

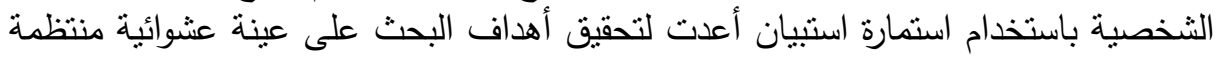

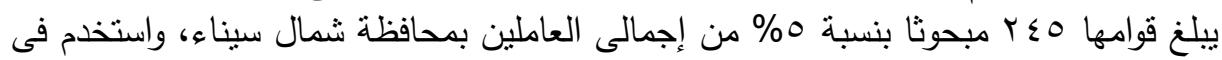

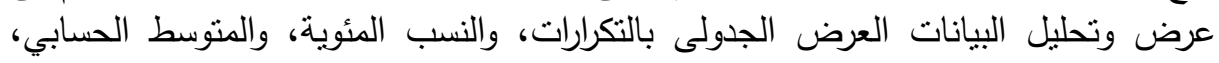

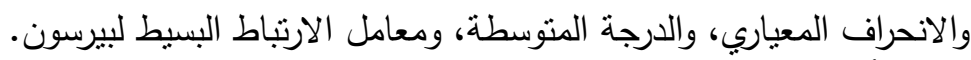

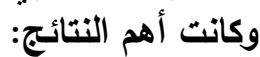

-الانخفاض النسبي لإدراك المبحوثين لمفهوم التنمية المستدامة وأهميتها، حيث وقع ما يقرب

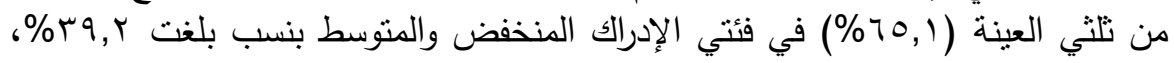

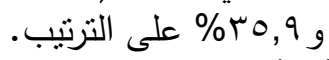

- أن أهم المصادر التى يستقى منها المبحوثين معلوماتهم جاءت مرنبة نتازليا وفقا للارجة

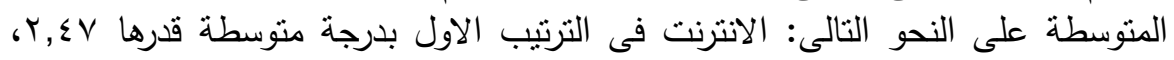

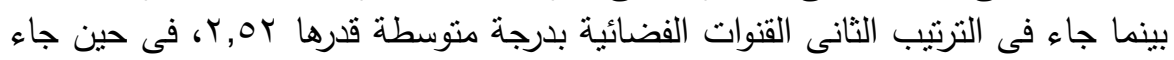

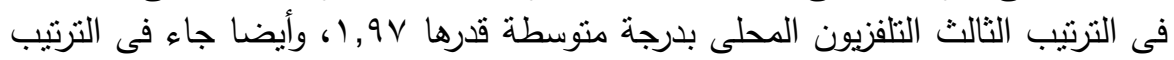

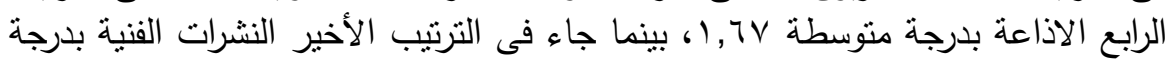
متوسطة قدرها ror, •. 
- وجود علاقة ارتباطية معنوية موجبة بين درجة ادراك ووعى المبحوثين بالتتمية المستدامة المبة المباتية

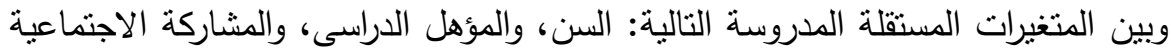

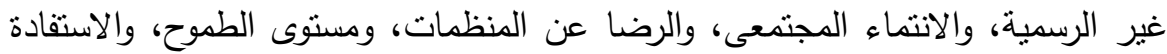

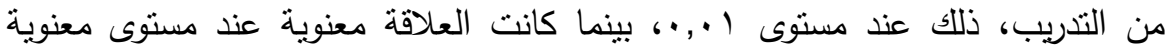

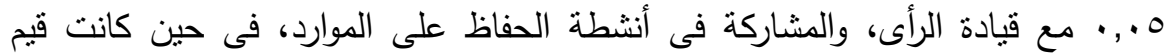

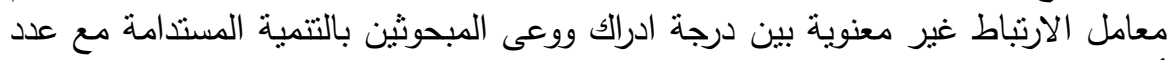

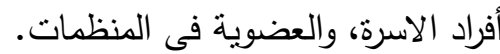

ويوصي البحث بضرورة بذل المزيد من الجهود لرفع المستوى المعرفى والتتفيذى من خلال

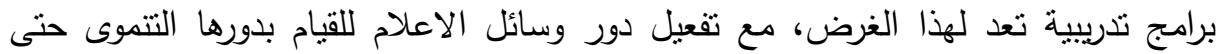
يحدث التغير المنشود مع التركيز على أنثكال التقديم الحوارية والتحليلات السياسية.

\section{xastl}

تعنبر شبه جزيرة سيناء من أهم المناطق الصحراوية حيث تمثل ج\% من مساحة مصر

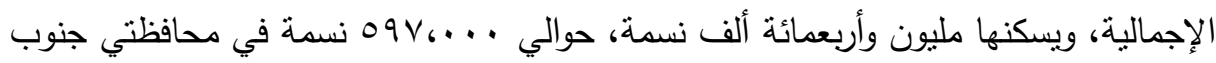
وشمال سيناء و. .1 الف نسمة في المنطقة الغربية من سيناء (السويس، الإسماعيلية، بورسعيد )، وتتكون شبة جزيرة سيناء إدارياً من محافظتين شمال سيناء، وجنوب سيناء. كما ولهاء

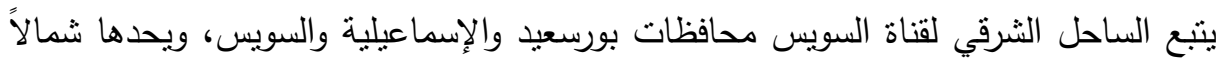
البحر المتوسط وغربا خليج السويس وقناة السويس وجنوباً البحر الأحمر وخليج العقبة، وهي

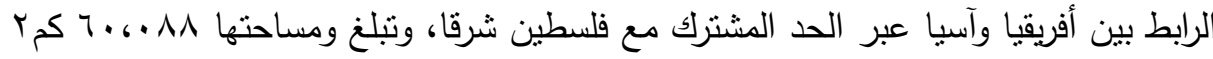

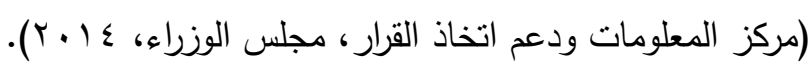
تمثل سيناء ثروة قومية وبعدا تتمويا لما تتمتع به من عوامل جذب ومحاولات للاستثمار والتتمية وتعد التتمية البشرية العمود الفقرى للتتمية المجتمعية وهى الركيزة الأساسية للتتمية والتعمير على ارض سيناء من خلال المحاور الأساسية فى مجال الصحة والتعليم والتربية والثقافة وإعداد الكوادر المتخصصة التى تتتاسب مع متطلبات التتمية. وتلعب وسائل الاعلام دوراً حيوياً فى عمليات التتمية الاقتصادية والاجتماعية وتبرز أهميتها بوجه خاص فى المناطق الريفية، وتكمن أهمية هذه الوسائل فى مقدرتها على بلى بيان

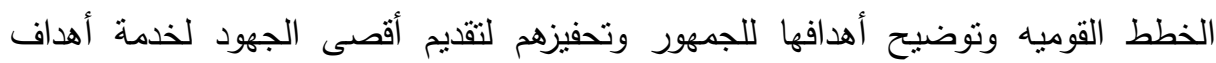


وقضايا المجتمع ومسايره تطوره ولا يتحقق ذلك إلا من خلال مخاطبة الرسالة الإعلامية

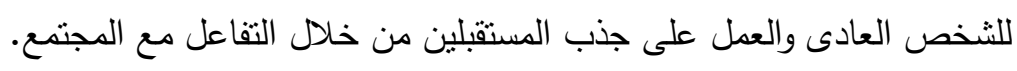

\section{And I2An}

علي الرغم من الأهمية الإستراتيجية التى تحظى بها سيناء إلا أنها عاندت لعدة عقود من إهمال متعمد أو غير متعمد أو ربما لاثتان معا، فأهملت عملية التتمية بها، مما جعل لأهل

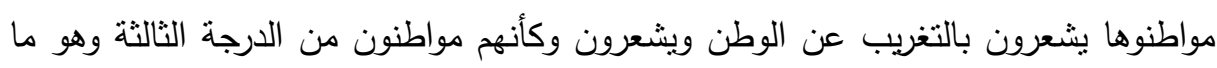

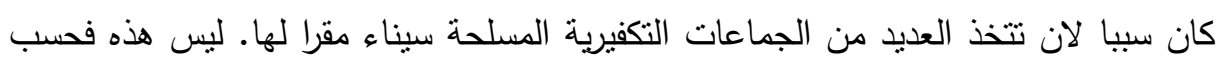

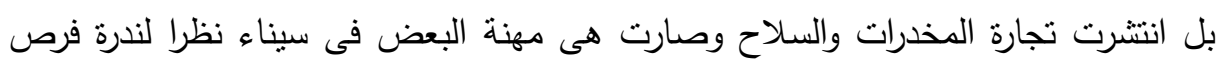
العمل المتوفرة.

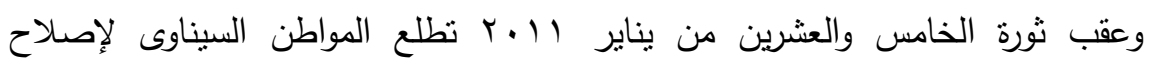
الأوضاع بسيناء، وبدء اهتمام متخذ القرار بها، وتحقيق أمنياتهم وتطلعاتهم إلا ان تخبط بنايط

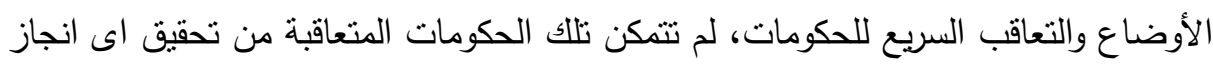

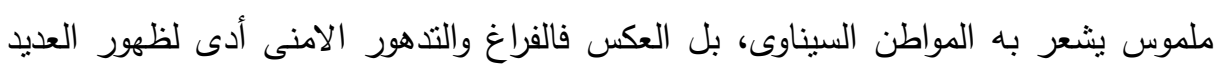

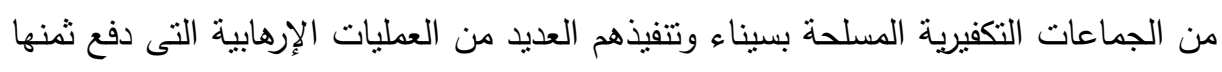
المواطن السيناوى المادى والمعنوى بتتويه صورته.

علي الرغم من تعدد الدراسات والبحوث السابقة ... Jonathan M. Harris، of Built Faculty

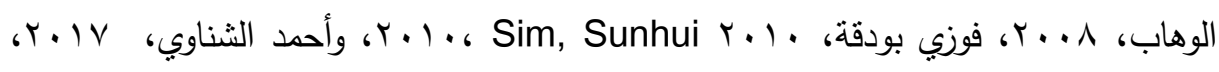
هناك حاجة ماسة لاجراء المزيد من الدراسة للمشكلات الاجتماعية والاقتصادية والبيئية التي تعوق التتمية في شمال سيناء ودور الاعلاميين في التوعية لمواجهتها، ومن هنا تحاول هذه الاهن

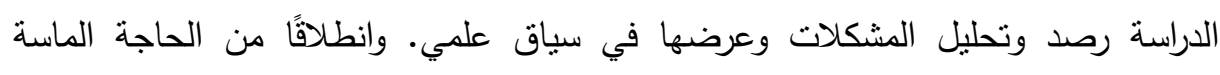
للاراسات في هذا المجال، وتتحصر مشكلة البحث في: • مدودية مصادر المعلومات عن حجم المشكلات التي تعوق التنمية في شمال سيناء. • • عدم وضوح دور الإعلام في خدمة قضايا التتمية وتوعية الجماهير بقضايا مجتمعهم.

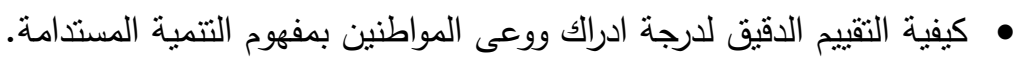

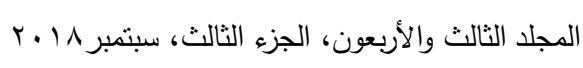




\section{أسئلا الهبهش}

ما هو دور الاعلام فى مواجهة المشكلات الاقتصادية والاجتماعية بمحافظة شمال سيناء ويتفرع هذا التساؤل الرئيسي إلى الأسئلة الفرعية التالية :

1- ما مصادر المعلومات التى يستقى منها المبحوثين معلوماتهم بمنطقة الدراسة. r- ما القضايا والمشكلات التى تتتاولها وسائل الاعلام. r- ما طبيعة العلاقة بين المتغيرات المستقلة المدروسة (السن، والمؤهل الدراسي، وعدد أفراد الاسرة، والانفتاح الثقافى، والعضوية فى المنظمات والمشاركة الاجتماعية غير الرسمية،

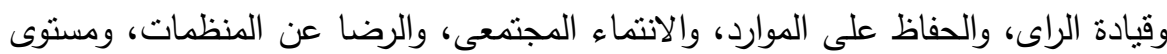

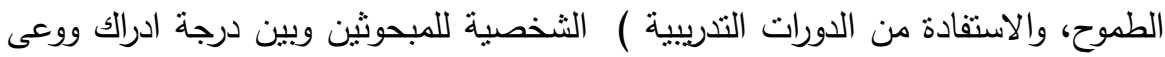
المبحوثين بمفهوم التتمبة المستخامة.

\section{الاهمباهيم الهيثية}

1- التعرف على الأهمية النسبية لمصادر معلومات المبحوثين بمنطقة الدراسة. r- التعرف على درجة ادراك ووعى المبحوثين بالتتمية المستدامة. r- التعرف على درجة تتاول وسائل الاعلام لأهم القضايا والمشكلات الاقتصادية دائه والاجتماعية.

ع- التعرف على المشكلات التى تواجه المبحوثين بمنطقة الدراسة، ومقترحاتهم لحلها. 0- طبيعة علاقة المتغيرات المستقلة المدروسة بدرجة ادراك المبحوثين بالتتمية المستدامة.

\section{هنوضر التراسة}

الفرض الأول: "توجد علاقة بين درجة ادراك ووعى المبحوثين بالتتمية المستدامة أهيتها واحتياجاتها وبين كل من المتغيرات المستقلة التالية: السن، والمؤهل الدراسي، وعدد أفراد الاسرة، والانفتاح الثقافى، والعضوية فى المنظمات والمشاركة الاجتماعية غير الرسمية، وقيادة 
الراى، والحفاظ على الموارد، والانتماء المجتمعى، والرضا عن المنظمات، ومستوى الطموح، والاستفادة من الدورات التدريبية. الفرض الثانى: لا نوجد علاقة بين درجة ادراك ووعى المبحوثين بالتتمية المستدامة وبين كل من المتغيرات المستقلة التالية: السن، والمؤهل الدراسي، وعدد أفراد الاسرة، والانفتاح

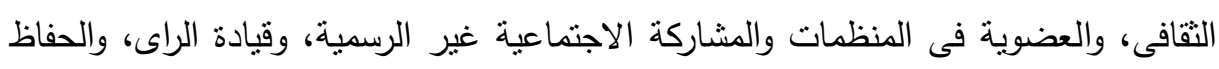

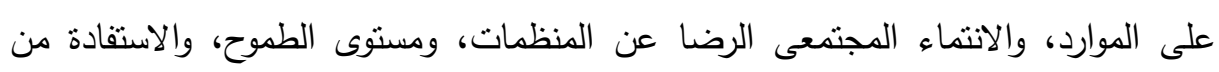
الدورات التدريبية.

\section{اللنظرية المويهمة للقواسما}

الاتجاهات العلمية في دراسة التنمية والإعلام التنموي: هناك من بصنف الاتجاهات النظرية في علم اجتماع التتمية إلى اتجاهات يضم كل منها نظرية أو أكثر، تثفق في المبادئ والاعل العامة،

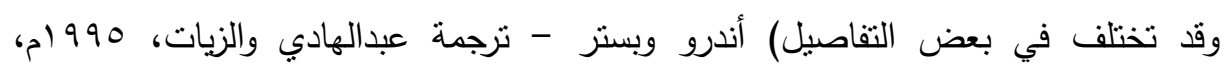
ص:9ץ(، وعلى الرغم من صعوبة تصنيف الاتجاهات النظرية المختلفة في دراسة واقع الدول

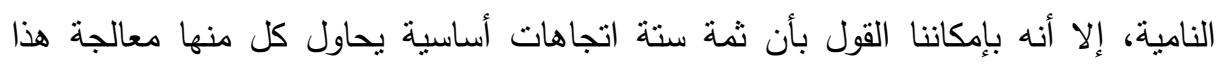

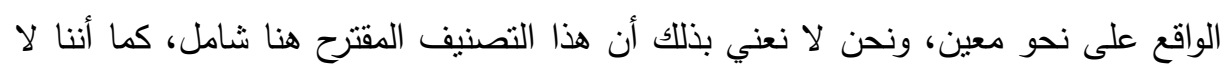
نذهب أيضاً إلى أن ثمة حدوداً فاصلة بينها، أما الاتجاهات النظرية الستة فهي (احمد لأهن

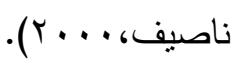

اتجاه النماذج أو المؤشرات، الاتجاه التطوري المحدث، الاتجاه الانتشاري، الاتجاه

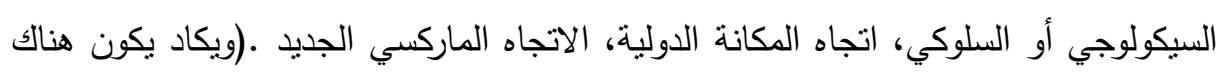

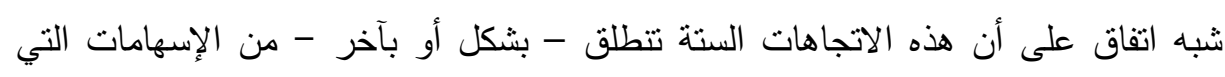
قدمها كل من كارل ماركس وماكس فيبر ، فاتجاه النماذج أو المؤشرات يستعين بفكرة النموذج بأنج

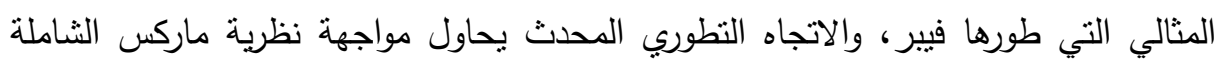

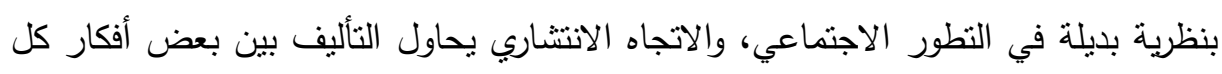

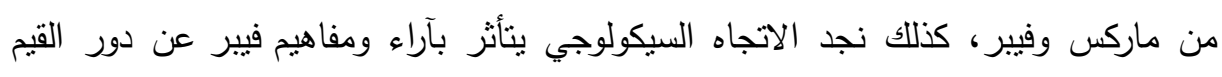

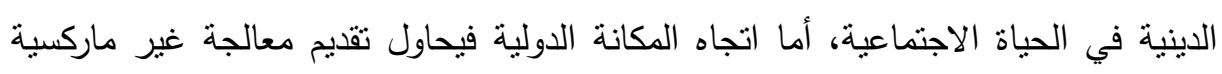

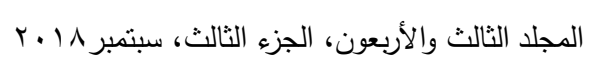


للنظام الدولي المعاصر، وأخيراً نجد الاتجاه الماركسي الجديد يحاول تعديل الصياغات

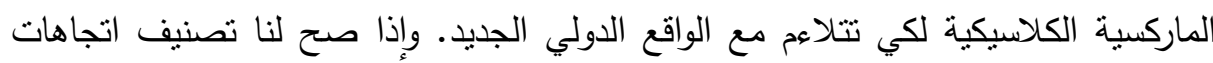
دراسة التتمية على اتجاهين: أحدهما مادي والآخر مثالي، فإن بإمكاننا القول إن ماركس قداند

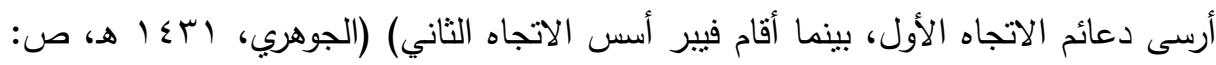
$\cdot(r \cdot \Lambda$ نظرية التأثير المباشر: وتنمئ نظرية الحقنة تحت الجلا او نظرية الرصاصة السحرية) (سادت هذه النظرية خلال العقود الاولى من القرن العشرين نظرة ثرى ان لوسائل الاتصال

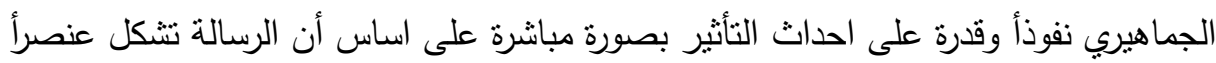

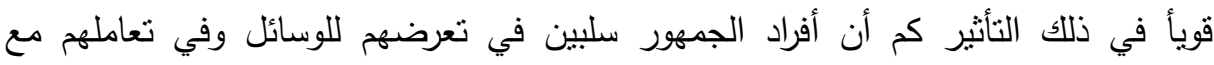

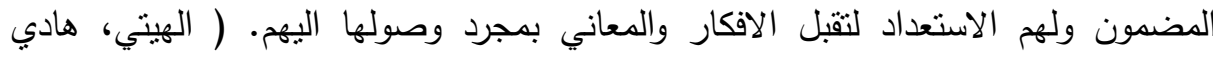

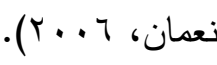
نظرية الاستخدامات والاشباعات: (وتسمئ نظرية الاستعمالات والرضا): تهتم هذه النظرية بدراسة الاتصال الجماهيري درسة وظيفية منظمة وهي ترى ان الجماهير فعالة في انتقاء افرادها لرسائل ومضمون مفضل من وسائل الاعلام وهي جاءت كرد فعل لمفهوم قوة الاعلام الطاغية. نظرية انتشار الابتكارات: وهي تفترض أن تدفق الاتصال ينم على مراحل وهويسمح

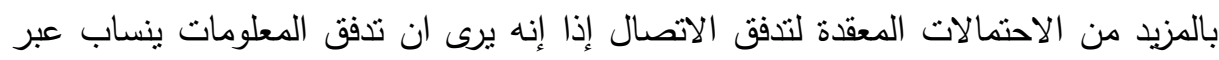

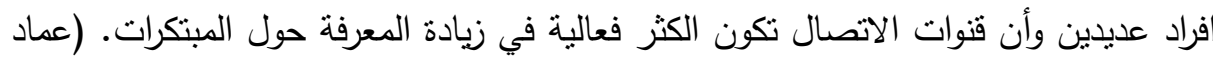

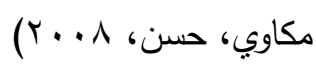

نظرية الإنماء الثقافي: وتنهى ايضاً بالغرس الثقافي ظهرت هذه النظرية في أمريكا خلال عقد السبعينيات كمنضور جديد لدراسة أثر وسائل الاعلام.نقول هذه النظرية، أن مداومة الإهة

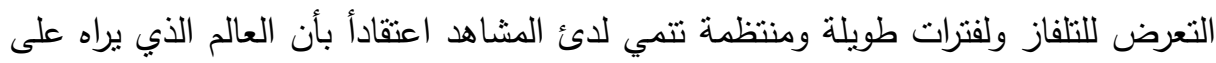

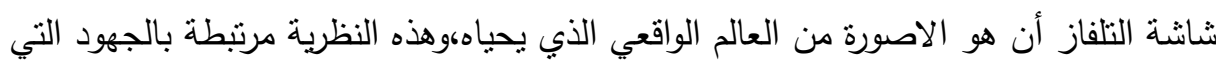


نظرية التبعية ( الاعتماد على وسائل الاعلام): محور هذه النظرية أن الجمهور يعتد الإند

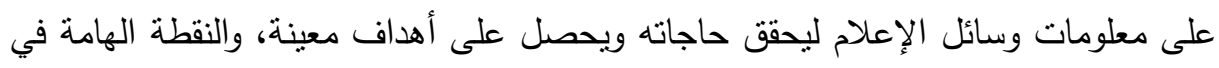

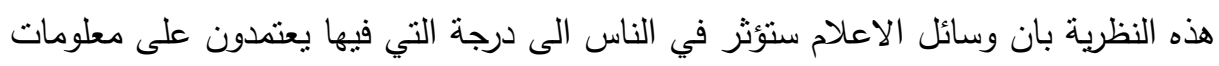

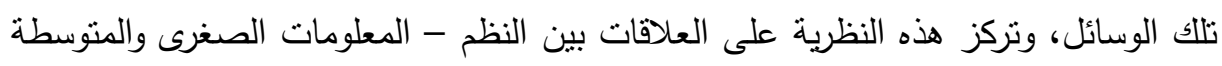
والكبيرة ومكوناتها.

نظرية الحتمية التكنولوجية: ترجع هذه النظرية الى جهود العالمان مارشال ماكلوهان

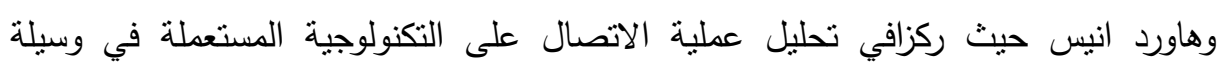

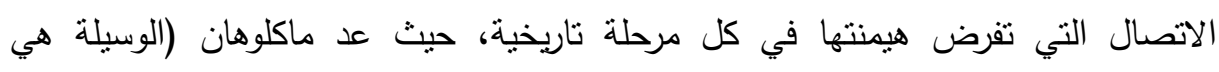

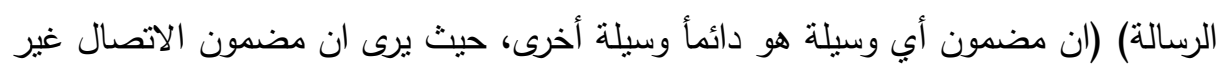

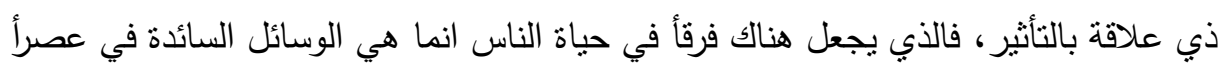
ما وليس مضمونها).

\section{التوراسايت الماريه}

دراسة لمياء محمد الإمبابى(ه . ㅜ) : استخدمت الدراسة منهج المسح بالعينة، وأداتها

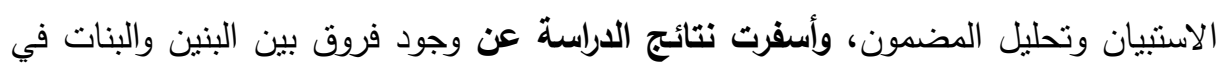

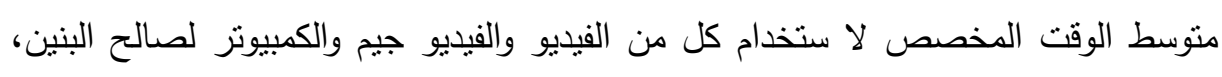

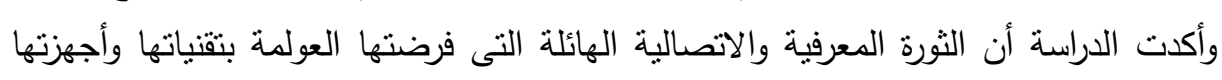

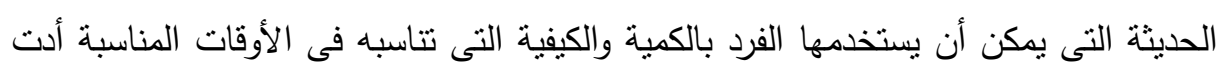

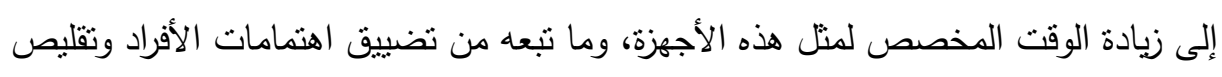

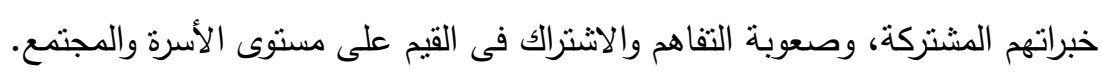

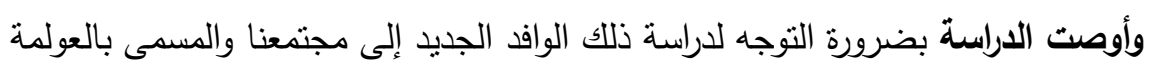

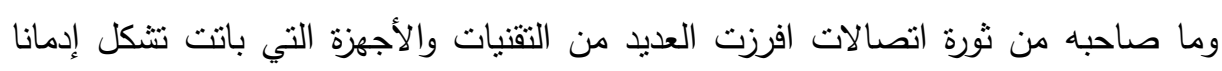

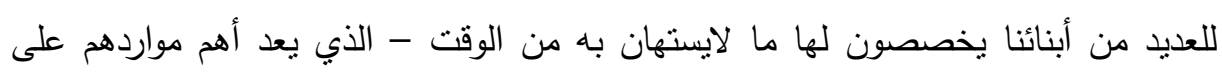

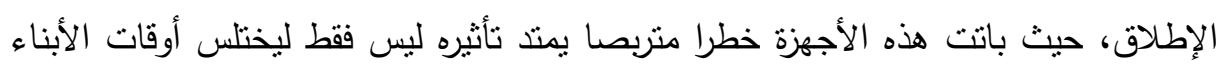
بل يمند إلى قيمهم ليبددها ومعها قدراتهم وطاقاتهم الإبداعية.

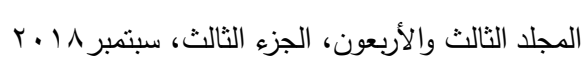




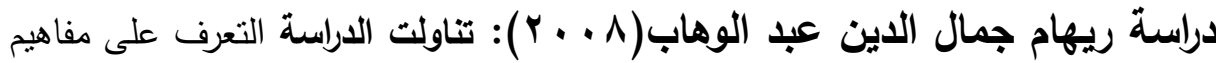
المشاركة الثعبية، وتحديد أسباب غيابها بالبرامج التتموية فى الدول النامية وبشكل خاص فى مصر، والتعرف على صور ومجالات المشاركة الثعبية، وتحديد العوامل الحاكمة للششاركة

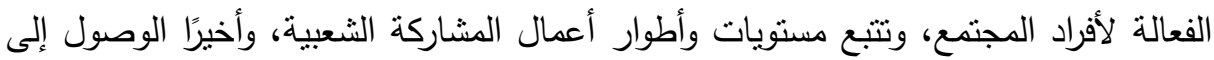
تحليل ورصد للدوافع الثخصية والحوافز المادية والمعنوية للمشاركة المطلوبة فى برامج الحفاظ التتموى. ومن أهم النتائج التى توصلت إليها الدراسة أن المشاركة الثعبية وسيلة وليست غاية لتفعيل برامج الحفاظ التتموي، وتكمن أهميتها فى تفعيل الدور الإيجابى للمستعمل من خلال مشاركته ليصبح أكثر خبرة وتأهلاً لتولى أمور نطاقه المحلى ومتابعة حمايته واستدامته بشكل سليم. - nen دراسة 2000: Jonathan M. Harris ، 2000 استطاعت وسائل الإعلام أن تحقق نجاحاً هائلاً في عمليات التتمية والتغيير وخاصة في الدول النامية وتبرز أهمية الإعلام في دوره

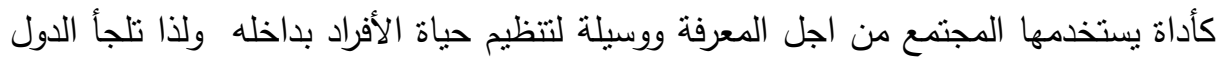

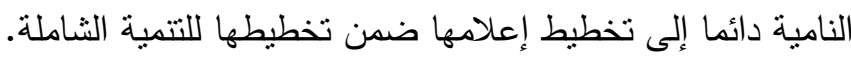
دراسة فوزي بودقة)( ـ ( ب): تتناول الدراسة إطار مفاهيم التتمية المستدامة المرتبطة بالتتمية العمرانية و يتطرق البحث لقضايا المحافظة على استدامة الأسواق الشعبية وإعادة تأهيلها، وتطويرها كوجهة اقتصادية، وتقافية، وسياحية، وإيجاد الحلول لمشاكل الأسواق الراهنة، وتحفيز الاستتمار فى الأسواق

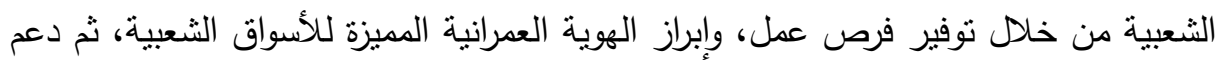

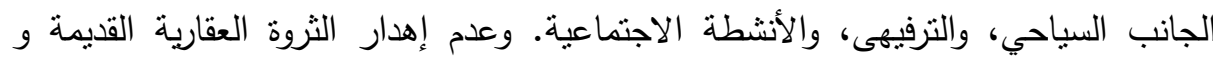

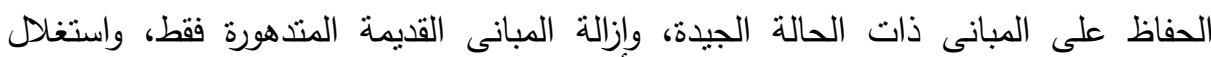
الفراغات بين المبانى كساحات شعبية للممارسة الرياضة للأهالي؛ وذلك للحفاظ على الروابط

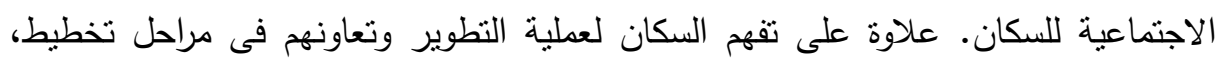

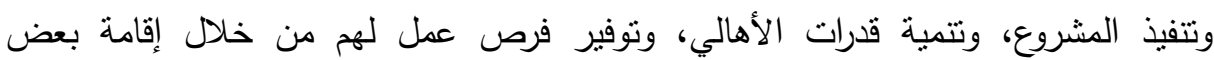


المشروعات غير ملوثة للبيئة، وعدم مركزية الخدمات لإمكانية استخدامها من قبل جميع الأهالى.

وقدمت الاراسة العديد من التوصيات تمنلت فى إعادة النظر فى التوزيع الوظيفى لبعض

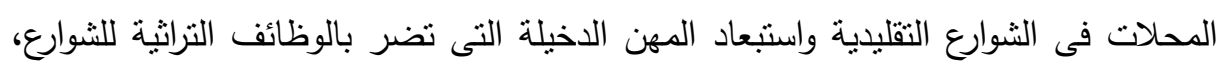
وإعادة صيانة وترميم الوجهات بمواد البناء الأصلية نفسها.

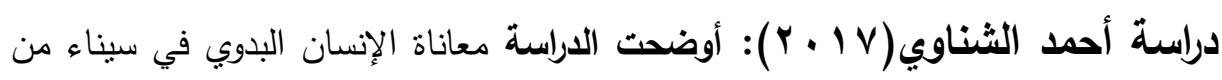
أزمة الهوية والانتماء، ويرجع ذلك إلى وجوده في ظل كيانات اجتماعية متعددة ومتعارضة تبدأ بالقبيلة وتتتهي بالدولة، مما يؤدى إلى تداخل عناصر الولاءات المحلية مع الولاءات الودئه الوطنية

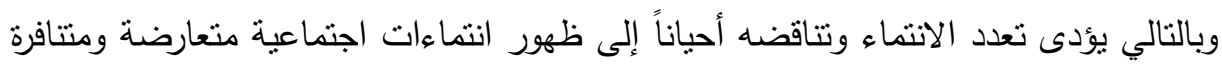

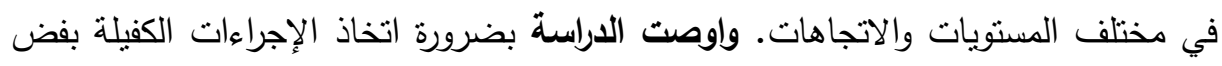
العزلة التاريخية لسيناء والتي فُرضت عليها خلال فترات طويلة من التاريخ المصري الحديث.

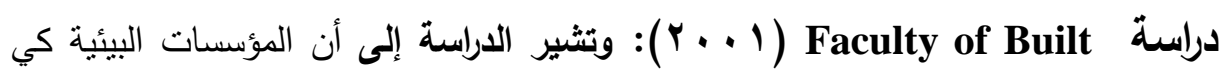
تحافظ وتطور التتمية المستدامة لديها لابد أن نقوم بتحديد واستخدام نظم إدارية معينة وذللك حسب ما تتطلبه الاستراتيجية البيئية المصممة لذلك. فكثير من المؤسسات تضع هذه لفئه الخطط

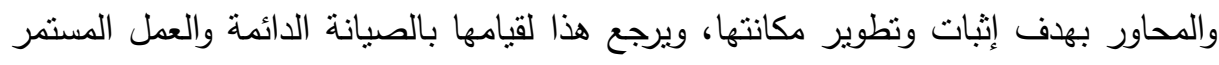

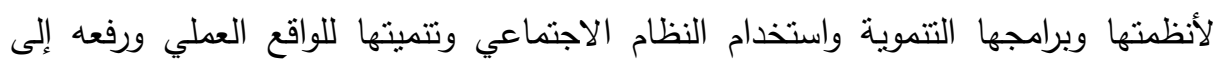

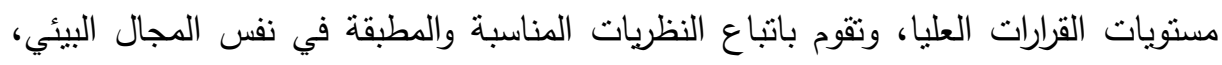

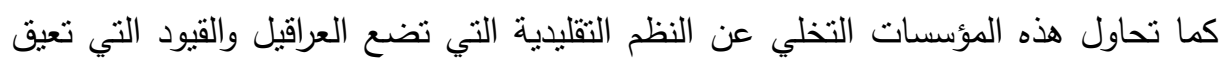
تتفيذ المشاريع التتموية. دراسة Sim, Sunhui ( • • ( ) ): عن المدخل المكاني لقياس ونمذجة أثر النمو الحضري على النظام البيئي؛ حيث إن النمو الحضري سبب مهم للمشاكل البيئية، وتركز هذه الدراسة

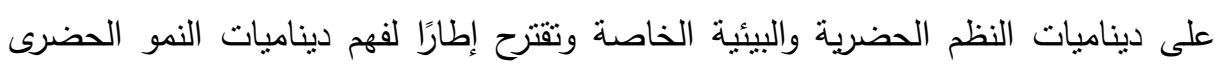
وخاصة استمرار المشاكل البيئية. وتوصلت الاراسة إلى أنه يمكن تحليل الامتداد المكانى

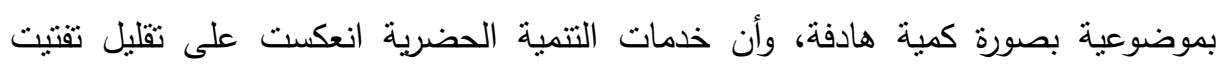
الرقعة الخضراء، وأن أكبر تحدى يواجه أداة التتمية الحضرية هو حماية النظم البيئية، وأخيرًا

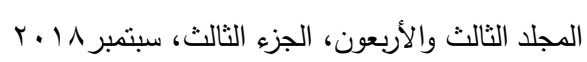




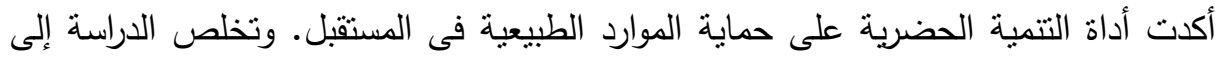

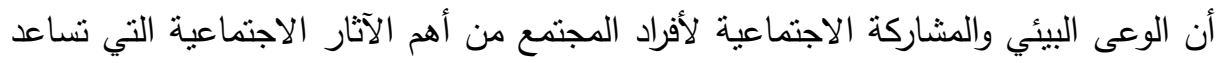

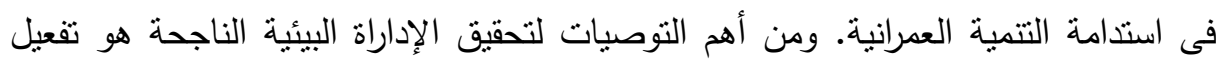
دور المنظمات غير الحكومية ومنظمات تتمية المجتمع المحلي في عمل دورات توعية للسكان بالأوضاع البيئية القائمة وخطورتها على صحتهم وممتلكاتهم، والاهتمام بمناقثة القضايا البيئية بشكل موضوعي مكثف داخل وسائل الإعلام المحلي.

\section{اجزاعايه الهيهث}

أولاً: منهج الدراسة: هوه المنهج الوصفي للتحليلل والمقارنة وبستخدم المسح الاجتماعي. في سبيل تحقيق هدف الدراسة واختبار فروضها، اعتمد الباحث في هذه الدراسة المنهج الوصفي التحليلي وأسلوب الدراسة الميدانية لجمع المعلومات والبيانات اللازمة لإتمام الدراسة. أما مصدر البيانات فقد تم الحصول عليها من مصدرين هما: أ- المصادر الثانوية: حيث اتجه الباحث في معالجة الإطار النظري للاراسة إلى مصادر البيانات الثانوية والتي تتمنل في الكتب والمراجع العربية والأجنبية ذات العلاقة، والدوريات والمقالات والتقارير، والأبحاث والدراسات السابقة التي تتاولت موضوع الدارسة، والبحث

$$
\text { والمطالعة في مواقع الإنترنت المختلفة. }
$$

ب- المصادر الأولية: وتتمنل في جمع البيانات الأولية ميدانياً، وذللك من خلال استخدام

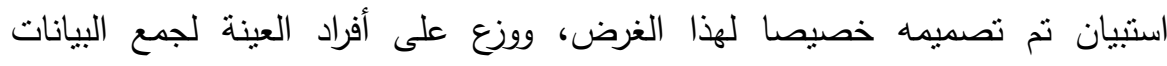

$$
\text { المطلوبة. }
$$

ج- أداة القياس: اعتمدنا في دراستتا الحالية على استمارة استبيان نم عرضها على المحكمين

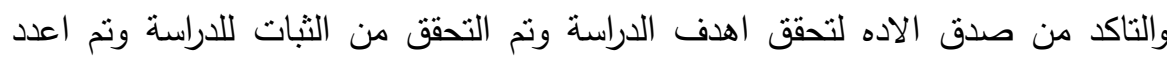
استمارة من قبل الباحثون للتحقق من المشكلات الاجتماعية والاقتصادية والبيئية التى ونى التهن

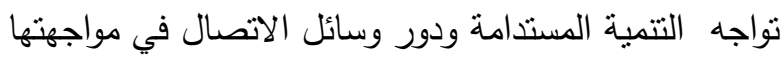


هـ -الخصائص السيكومترية لأداة القياس: للنأكد من أداة الدراسة المستخدمة تستطيع أن تقيس ما وضعت من أجله لتقبسه يجب قياس الخصائص السيكومنرية لهذه الأداة وهذه الخصائص تتمنل في الصدق والثبات وسنتطرق إلى كيفية حساب كل خاصية من هاتين الخاصيتين.

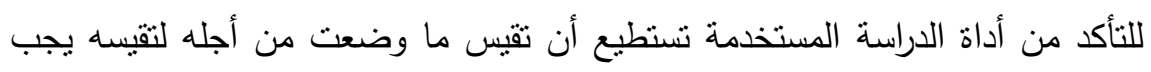

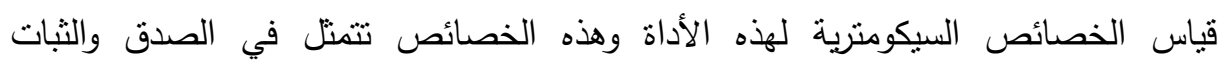
وسنتطرق إلى كيفية حساب كل خاصبة من هاتين الخاصيتنين.

1- الصدق في تحدب أبعاد وعبارات المقياس: قام الباحث بالإطلاع على مائ ما أسنطاع

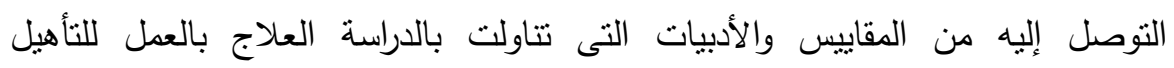
الاجتماعي والنفسي لمتعطي المخدرات، وإطلع على بعض المقاييس ذات الصلة والابعاد

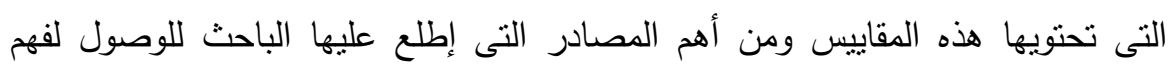

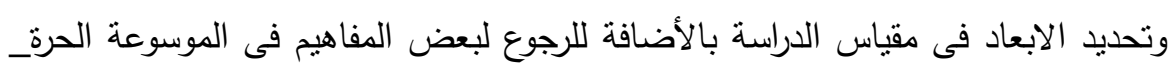

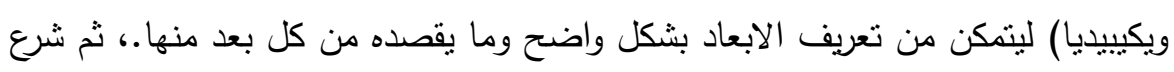

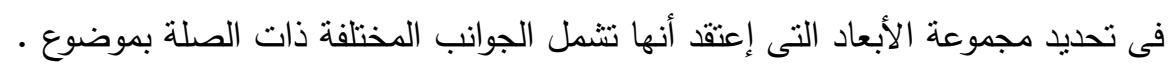
r - حساب صدق المقياس والثبات: إعتمدت الدراسة فى قياس صدق المقياس على على طريقة

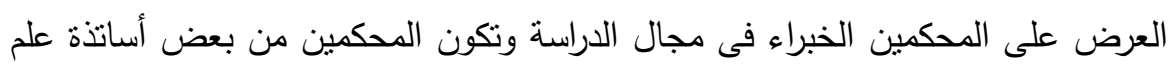

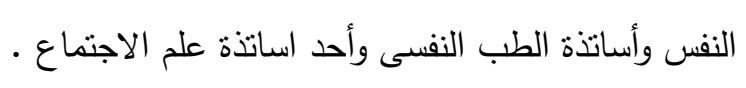

اختبار الصدق الإحصائي للمقياس: يقصد بالصدق الإحصائي في عطية القياس أن أداة

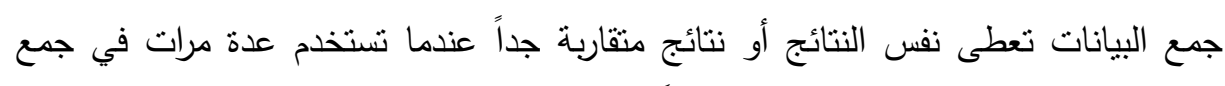
البيانات عن مفهوم واحد يفترض ثباته أيضاً.

ويتم إيجاد الصدق الإحصائي عن طريق(معامل الارتباط) وهو عباته إضارة عن ارتباط بين مجموعتين من الدرجات التي تم الحصول عليها عن طريق اختبار واحد أو صورتين متكافئتين للاختبار، ويمكن تحديد أهم الوسائل الإحصائية لثبات المقياس من خلائ من الطرق التالية:

$$
\begin{aligned}
& \text { ب- طريقة الاختبارات المتكافئة. } \\
& \text { أ- طريقة إعادة الاختبار • } \\
& \text { د- طريقة تحليل التباين. } \\
& \text { ج- طريقة التجزئة النصفية. }
\end{aligned}
$$


واعتمد الباحثون في التأكد من ثنات المقياس على طريقة( إعادة الاختبار) حيث قام

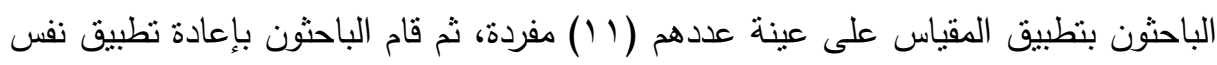

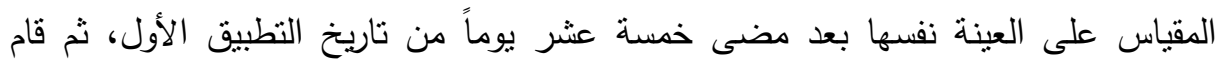

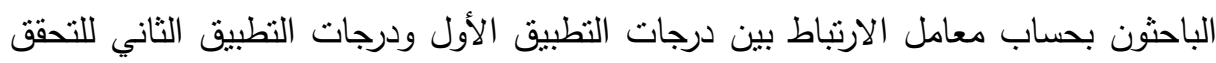

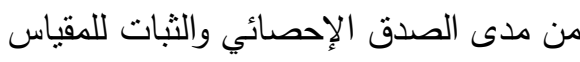
التحليل الاحصائي: نم الاستعانة بعدد من الأساليب الإحصائية لتحليل بيانات هذه الدراسة والتي تتمثل في التكرارات، والنسب المئوية، والمتوسط الحسابي، والانحراف المعياري، والدرجة المتوسطة، ومعامل الارتباط البسيط لبيرسون.

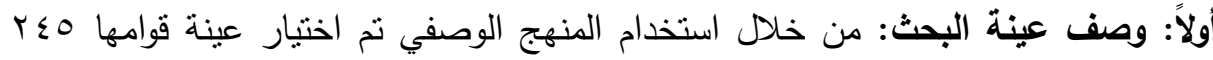
مبحوثا من العاملين داخل النطاق الجغرافي لمحافظة شمال سيناء، ومن خلال إعداد استمارة استنيان تم جمع بياناتها من عينة من المبحوثين بمركزى العريش وبئر العبد خلال شهرى

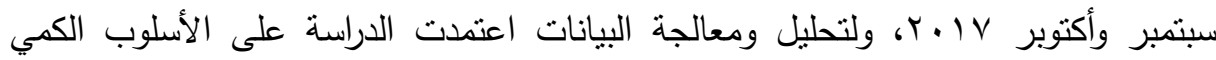

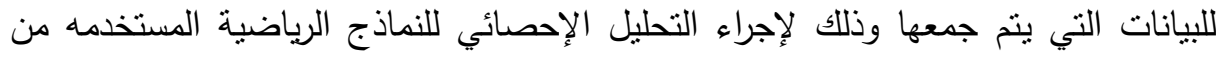
ناحية واختبار صحة الفروض من ناحية أخرى. أ-توصبف المتغيرات الشخصبة للمبحوثين:

1 - ألسن: ويقصد به سن المبحوث وقت استيفاء الاستبيان، ويعبر عنه برقم مطلق.

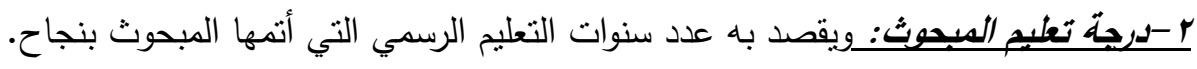

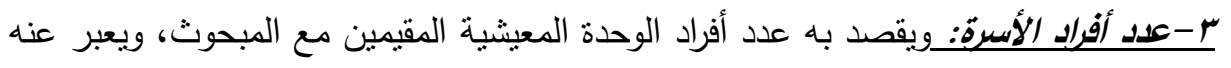
برقم مطلق.

ع-درية الانفتاح الثقافحف. ونم قياسه من خلال استيفاء رأي المبحوث في خمس عبارت،

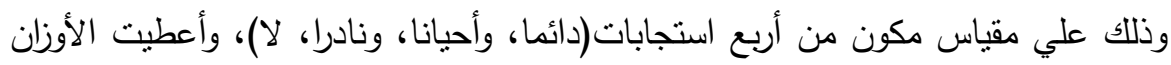
(T، r، (، صفر)علي الترتيب، وقد تراوح المدى النظري للمقياس ما بين ( صفر - 10 
ه-درية العضويةّة فحى المنظمات الاجتماعية: وتم قياسه من خلال مشاركة المبحوث في ستة منظمات محلية وذلك علي مقياس مكون من استجابتين( عضو ، غير عضو)، وأعطيت الأوزان( (، وصفر)، وقد تراوح المدى النظري للمقياس ما بين ( صفر - 1 د درجات).

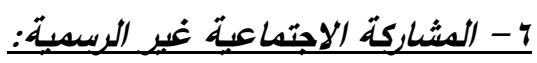

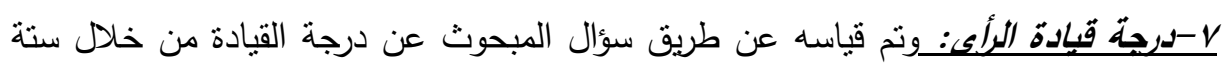
عبارات تعكس درجة القيادة من خلال حل المشكلات الزراعية وغير الزراعية بالرأى

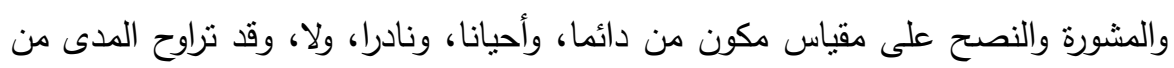

$$
\text { (صفر -1 ا درجات). }
$$

1- درجة المشاركتة فح أنشطة الحفاظ على المولد الارضية والمائية: تم قياسة عن طريق سؤال المبحوث عن مشاركتة فى الانشطة التى تهدف فى الحفاظ على الموارد من خلال

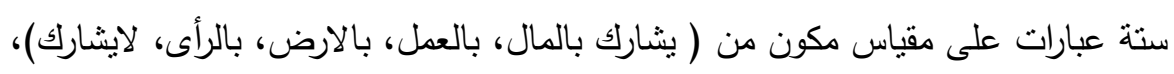

$$
\text { وقد نراوح المدى ( صفر - ع ب درجة). }
$$

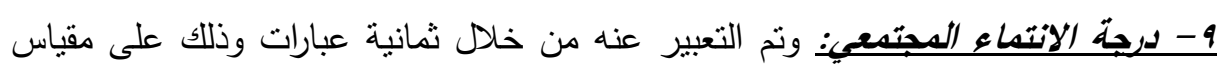

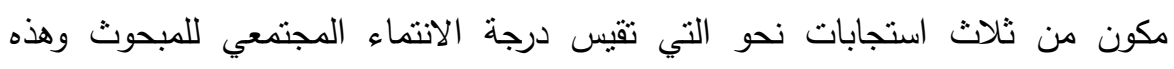

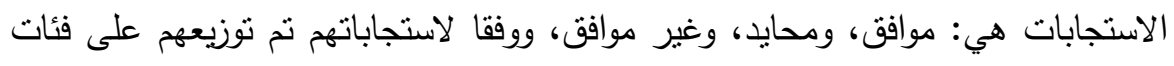

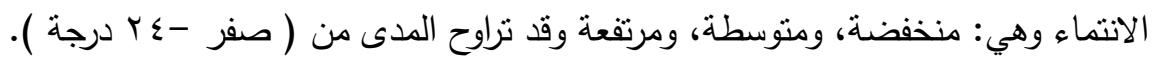

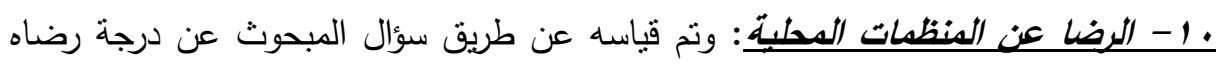

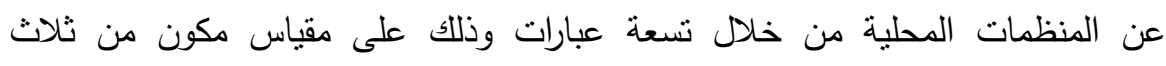
استجابات ( راضى، ولحد ما، وغير راضى )، وقد تراوح المدى من (صفر -1 أ درجة).

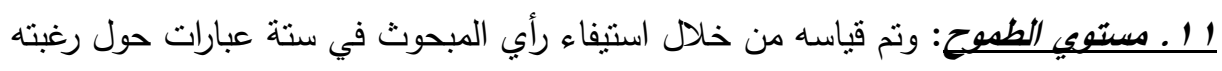

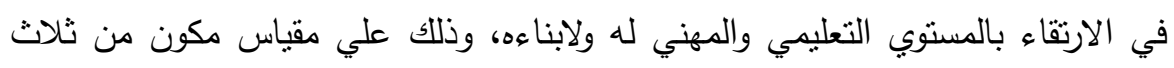

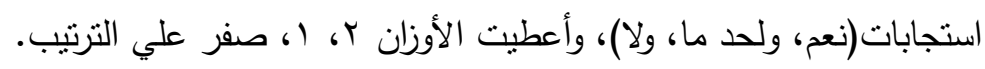

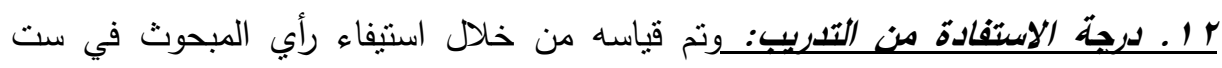

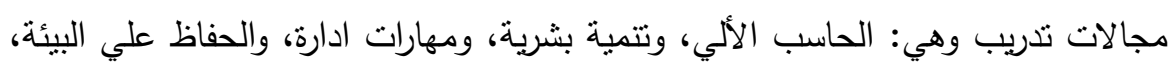


والانتاج النباتي، والاتتاج الحيواني، وذلك علي مقياس مكون من ثلاث استجابات(مرتفعة،

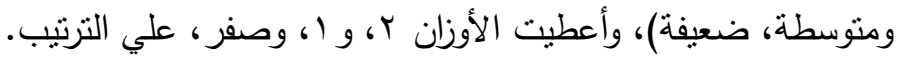

ب - المتغير التابع: إدراك ووعى المبحوثين بالتتمية المستدامة الاولويات والاحتباجات وأهمية الأورية

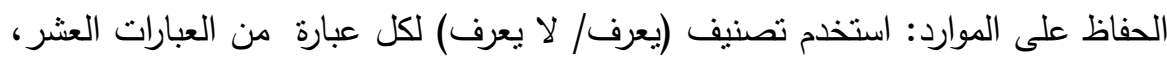
وأعطيت درجات (1)، (صفر) حسب استجابة المبحوث، وأعنبر حاصل جمع الدرجات التي حصل عليها مؤشرا كمبا لقياس مستواه المعرفي ووفقا لذلك نم توزيعهم على فئات درجة وعى الزراع وهي: منخفضة، ومتوسطة، ومرتفعة، وقد نراوح المدى من ( صفر موني -

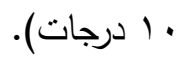

ثانياً: الاهمية النسبية لمصادر المعلومات: حيث ثم سؤال المبحوثين عن مصادر معلوماتهم 1

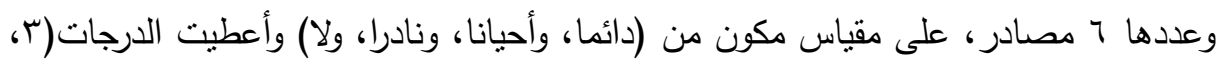

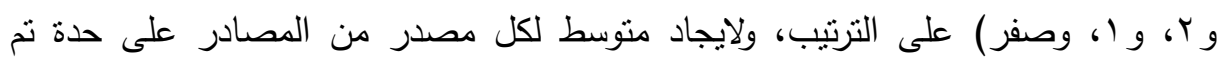

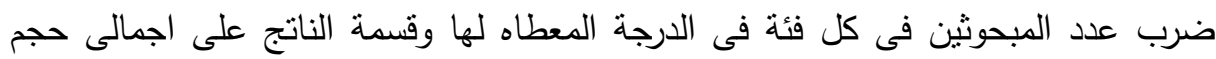

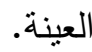

ثالثاً: درجة تناول وسائل الاعلام للقضايا والمشكلات: تم قياسه من خلال استيفاء رأى المبحوثينعن تسعة مشكلات اقتصادية واجتماعية ومجتمعية وكيفية مواجهتها من خلال وسائل

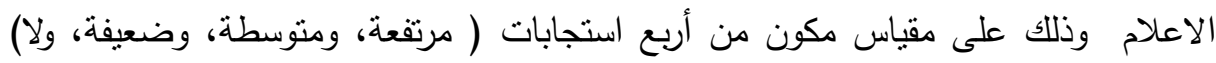

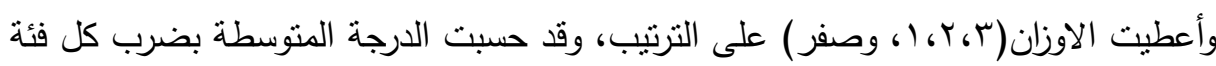
فى الوزن والقسمة على حجم العينة، وبذلك أمكن ترتيب الوسائل الاعلامية.

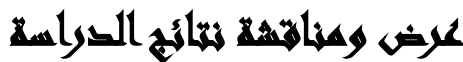

ا - المتغيرات الشخصية للمبحوثين: تشير النتائج الواردة بالجدول رقم (1) أن ما يزيد

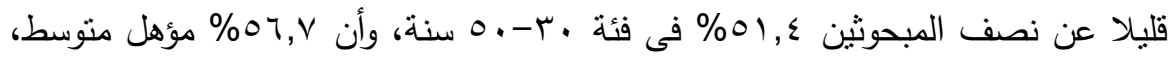

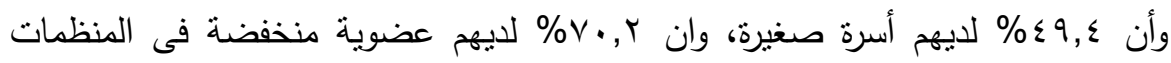
الاجتماعية، وأن حوالى نصف المبحوثين r, •0\% لديهم مستوى طموح بدرجة مرتفعة، 


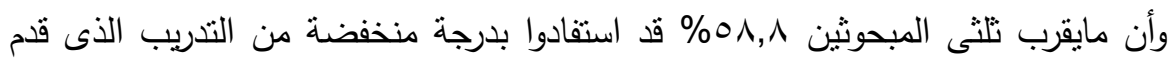

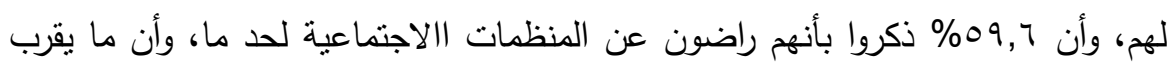

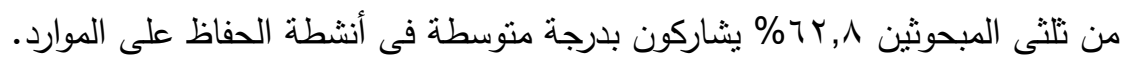
جدول رقم(1): توزيع المبحوثين وفقا للخصائص الثخصية

\begin{tabular}{|c|c|c|c|c|c|}
\hline$\%$ & عدد & المتغير & $\%$ & عدد & المتغير \\
\hline & & V- V- الاستفادة من التخريب & & & 1-السن \\
\hline $0 \wedge, \wedge$ & $1 \leq \varepsilon$ & ضعيفة (صفر - ع درجات) & $1 \%, 1$ & rY & ( آقل من • r سنة) \\
\hline$r q, \xi$ & VY & منوسطة (0- 1 درجات ) & $Y, 1,7$ & or & 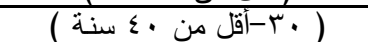 \\
\hline \multirow[t]{2}{*}{$11, \wedge$} & rq & مرتفعة ( 9 درجات فأكثر ) & $r q, \Lambda$ & $V T$ & 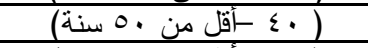 \\
\hline & & 1- درجة كفابة التدريب & $\mu 0,0$ & $\lambda V$ & 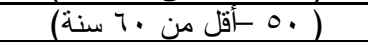 \\
\hline$V Y, Y$ & $I V V$ & غبر كافية (صفر - ع درجات) & & & با-درجة تعليم المبحوث \\
\hline 10,1 & $r v$ & لحد ما ( & $07, V$ & 1149 & مؤهل متوسط \\
\hline \multirow[t]{2}{*}{$I Y, V$} & M & كافية ( 9 درجات فأكثر) & $r q, 7$ & $9 V$ & جامعي \\
\hline & & 9- الرضا عن منظمات محلية & $r, V$ & 9 & دراسات عليا \\
\hline$r 0, V$ & $\pi$ & غبر راضي (صفر - 7 درجات) & & & r-عدد أفراد الآسرة \\
\hline 09,7 & $1 \leqslant 7$ & 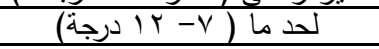 & $\varepsilon 9, \varepsilon$ & $|Y|$ & أسرة صغيرة(أقل من V أفراد) \\
\hline \multirow[t]{2}{*}{$1 \leqslant, V$} & צ & راضى ( זا درجة فأكثر) & $r 0,1$ & $\Lambda 7$ & أسرة متوسطة( V- •أفراد) \\
\hline & & • • الانفتاح الثقافي & 10,0 & rA & أسرة كبيرة (أكثر من · ا أفراد) \\
\hline 10,9 & rq & ضعيف (أقل من 0 درجات) & & & ع-العضوية فى المنظمات \\
\hline$\sum 7,9$ & 110 & متوسطة (0- ، درجات) & $V \cdot, r$ & IVY & عضوية منخفضة ( - Y درجة) \\
\hline \multirow[t]{2}{*}{$r v, r$} & 91 & مرتفعة( (ل درجة فأكثر) & $r q, \wedge$ & vr & عضوية متوسطة ( r- ع درجة) \\
\hline & & |11- درجة القيادية & & & عضوية مرتفعة ( V-0 درجة) \\
\hline 10,0 & rᄉ & قيادة منخفضة (صفر - & & & 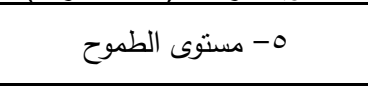 \\
\hline $0 \wedge, \wedge$ & $1 \leq \varepsilon$ & قيادة منوسطة ( V- r ا درجات) & 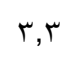 & $\wedge$ & ضعيف ( صفر - ع درجات) \\
\hline \multirow[t]{2}{*}{ YO,V } & 74 & قيادة مرتفعة ( سا درجة فأكثر) & $\sum 7,0$ & $11 \varepsilon$ & منوسط (0- ^ درجات) \\
\hline & & بَ آ - درجة المشاركة فى الحفاظ & $0 ., r$ & Ir & مرتفع ( 9 \\
\hline r^, 9 & VI & مشاركة ضعيفة (صفر د & & & 7- الانتماء للمجتمع المحلى \\
\hline$T Y, \Lambda$ & $10 \leqslant$ & مشاركة منوسطة ( & 19,7 & $\leqslant 1$ & صفر - 1 درجات \\
\hline \multirow[t]{2}{*}{$\Lambda, r$} & $r \cdot$ & مشاركة مرتفعة ( 1 ( أدرجة & $r v, \Lambda$ & 71 & 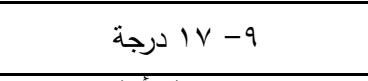 \\
\hline & & & Or,T & 119 & 1/ ا درجة فأكثر \\
\hline
\end{tabular}


تثتير النتائج الواردة بالجدول رقم (Y) أنه يمكن ترتيب المصادر التى يستقى منها

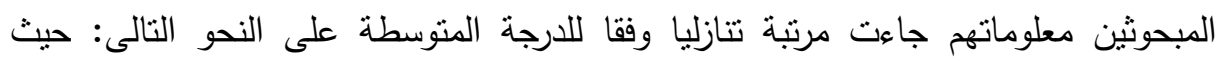

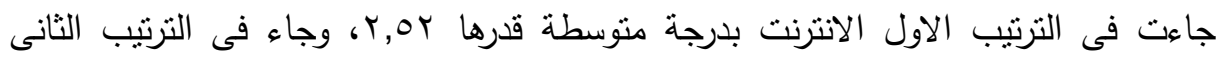

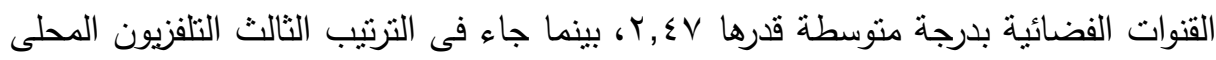

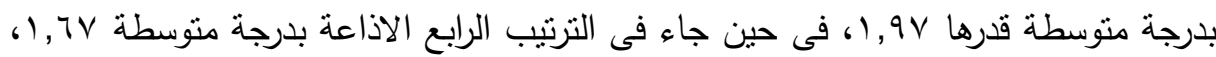

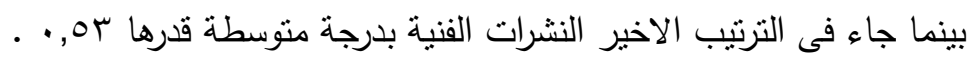

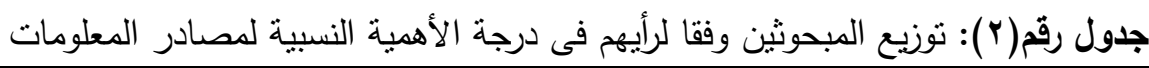

\begin{tabular}{|c|c|c|}
\hline الترتيب & المتوسطة & المصدر \\
\hline$\overline{11}$ & T,OY & الانترنت \\
\hline$r$ & $Y, \leqslant V$ & القنوات الفضائية \\
\hline$\mu$ & $1,0 \mathrm{~V}$ & التلفزيون المحلي \\
\hline$\varepsilon$ & T, rY & الاذاعة \\
\hline 0 & $1, \cdot r$ & الصحف \\
\hline $\mathrm{V}$ &., 97 & المجلات \\
\hline$\Lambda$ & $\cdot, \mathrm{V} \varepsilon$ & المطبوعات الارشادية \\
\hline 9 & $\cdot, 0 \mathrm{~T}$ & النشرات الفنية \\
\hline
\end{tabular}

$$
\text { المصدر: نتائج التحليل الاحصائى. }
$$

\section{r- إدراك ووعى المبحوثين بالتتمية المستدامة الاولويات والاحتياجات وأهمية}

الحفاظ على الموارد الارضية والمائية: أظهرت النتائج الواردة بالجدول رقم (r) الانخفاض النسبي لإدراك المبحوثين لمفهوم التتمية المتندامة وأهميتها والحفاظ على الى الموارد، حيث وقع ما يقرب من تلثي العينة (10,1\%) في فئتي الإدراك المنخفض

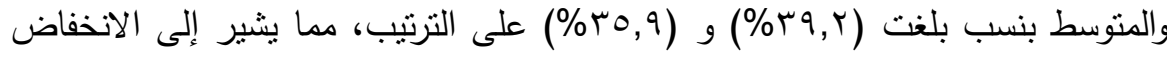
النسبى لمستوى إدراكهم لمفهوم التتمية المستدامة ودورها فى حل المشكلات. 
جدول رقم(ץ): توزيع المبحوثين وفقا لدرجة إدراكه بالتتمية المستدامة الاولويات والاحتياجات وأهمية الحفاظ على الموارد

\begin{tabular}{|c|c|c|}
\hline$\%$ & عدد & درجة الإدراك \\
\hline$\overline{r q, Y}$ & 97 & منخفضة ( آلقل من ع درجة ) \\
\hline$\Gamma 0,9$ & $\Lambda \Lambda$ & متوسطة ( ؟- 7 درجة ) \\
\hline$r \varepsilon, q$ & 71 & مرتفعة ( V - • • درجة ) \\
\hline $1 \ldots$ & $T \leqslant 0$ & الاجمالى \\
\hline
\end{tabular}

المصدر: نتائج التحليل الاحصائى

\section{r- التعرف على درجة تناول وسائل الاعلام لأهم القضايا العامة والمشكلات}

الاقتصادية والاجتماعية: تبين من النتائج الوادة بالجدول رقم( ع) انخفاض الدرجة المتوسطة الاجمالية لدرجة تتاول ومواجهة وسائل الاعلام للقضايا والمشكلات الاجتماعية والاقتصادية والمجتمعية والتى بلغت اقصاها ثلاث درجات حيث تراوحت مابين منوسطة

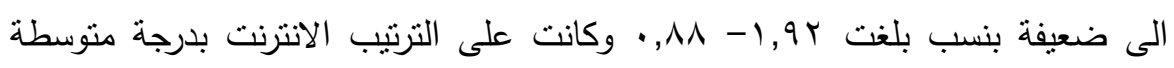

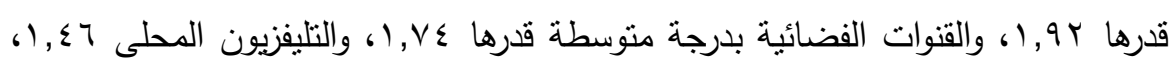

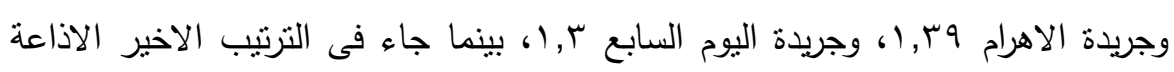

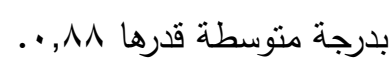

وفيما يتعلق بطبيعة المشكلات فقد جاءت مشكلة النطرف الفكرى ( الارهاب) فى مقدمة المشكلات وكانت أهم الوسائل هى: الانترنت، والقنوات الفضائية، والقنوات المحلية،

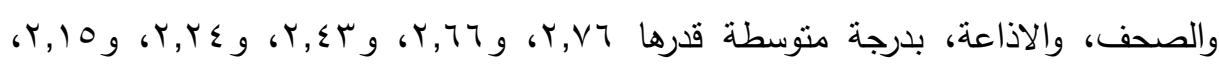

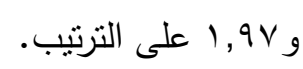

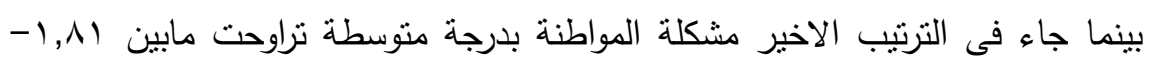

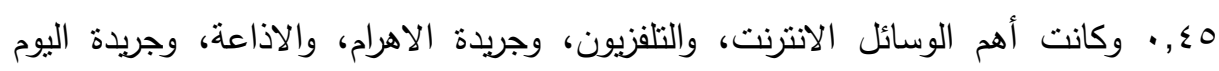
السابع. 
جدول رقم(؛ ): دور وسائل الاعلام فى مواجهة المشكلات والقضايا العامة

\begin{tabular}{|c|c|c|c|c|c|c|}
\hline الاذاعة & & الصحف & & التلفزيون & الانترنت & \\
\hline & اليوم السابع & الاهرام & محلية & فضائية & & القضايا العامة والمشكلات \\
\hline $1,9 \vee$ & $r, 10$ & $r, Y \varepsilon$ & $r, \varepsilon r$ & $r, 74$ & $r, \vee\urcorner$ & (النطرف الفكرى الارهابَ) \\
\hline $1, \cdot r$ & 1, ro & $r, \cdot 9$ & $r, 1 \varepsilon$ & r,or & $r, 7)$ & المشكلات الصحة الصامة) \\
\hline$\cdot, \wedge \varepsilon$ & וז & $1, \wedge \varepsilon$ & $r, \cdot r$ & 1,91 & $r, .9$ & $\begin{array}{c}\text { المشكلات التعليمية } \\
\text { (الامية ) }\end{array}$ \\
\hline זדית & $r, i r$ & $\cdot, \vee \vee \varepsilon$ & $\cdot, \wedge \wedge$ & 1,70 & 1,11 & المشكلات الاقتصادية \\
\hline$\cdot, \mathrm{VV}$ & $\cdot, 9 \wedge$ & $1, \leqslant 0$ & $1, V \varepsilon$ & $r, r T$ & $r, r_{4}$ & المشكلات الاقتصادية \\
\hline$\cdot, \leqslant 9$ & $\cdot, \wedge 4$ & $1, \varepsilon \varepsilon$ & 1,11 & $\cdot, 01$ & $1, r \varepsilon$ & 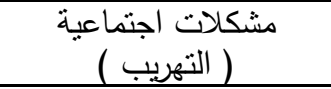 \\
\hline$\cdot, \wedge 0$ & $1, \varepsilon 7$ & $1, Y Y$ & $\cdot, 79$ & $1, r 4$ & 1,7 & مشكلات الجتماعية الادمان \\
\hline$\cdot, \vee \vee 9$ & $\cdot, 97$ & 1,14 & 1,04 & $1,1 \varepsilon$ & 1,01 & 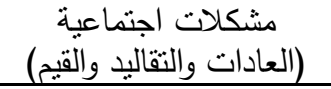 \\
\hline$\cdot, \leqslant 0$ & $\cdot, 74$ & $\cdot, \mathrm{TV}$ & $\cdot$,Or & 1, or & 1,11 & 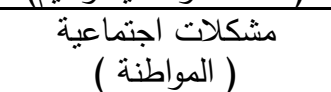 \\
\hline$\cdot, \wedge \wedge$ & $1, r$. & 1,49 & $1, \leqslant 7$ & $1, v \varepsilon$ & 1,94 & الدرجة المتوسطة الاجمالية \\
\hline
\end{tabular}

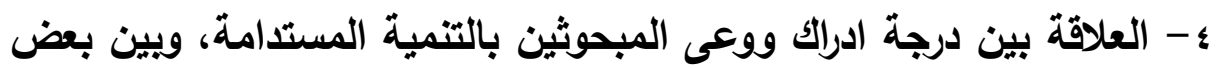
المتغيرات المستقلة المدروسة: للتعرف على العلاقة بين درجة ادراك ووعى المبحوثين بالتتمية المستدامة، والمتغيرات المستقلة المدروسة، تم صياغة الفرض البحثى تهى التالى "توجد علاقة بين درجة ادراك ووعى المبحوثين بالتتمية المستدامة أهميتها واحتياجاتها وبين كل من المتغيرات المستقلة التالية: السن، والمؤهل الدراسي، وعدد أفراد الاسرة، والانفتاح الثقافى، والعضوية فى المنظمات والمشاركة الاجتماعية غير الرسمية،

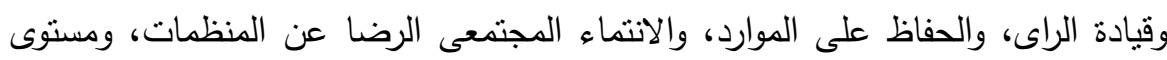
الطموح، والاستفادة من الدورات التدريبية. 
كما تم صياغة الفرض الإحصائى التالى" لا نوجد علاقة بين درجة ادرالك ووعى المبحوثين بالتتمية المستدامة وبين كل من المتغيرات المستقلة التالية : السن، والمؤهل الدراسي، وعدد أفراد الاسرة، والانفتاح الثقافى، والعضوية فى المنظمات والمشاركة الاجنماعية

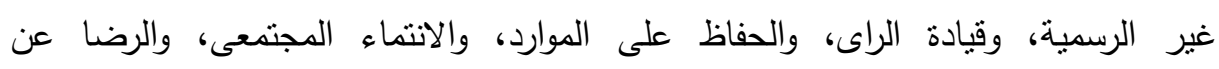
المنظمات، ومستوى الطموح، والاستفادة من الدورات التدريبية. وللتأكد من صحة هذا الفرض نم استخدام معامل الارتباط البسيط لبيرسون، وتوضح النتائج جدول رقم(0) أن قيم معامل الارتباط البسيط لبيرسون بين درجة ادراك ولى ووعى لإنى

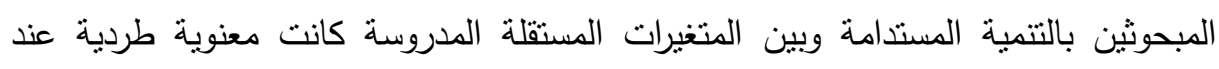

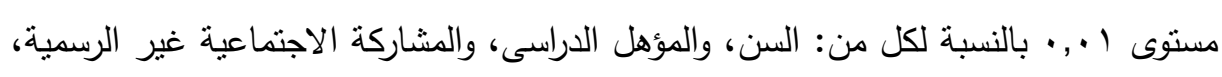
والانتماء المجتمى، والرضا عن المنظمات، ومستوى الطموح، والاستفادة من التدريب، بينما

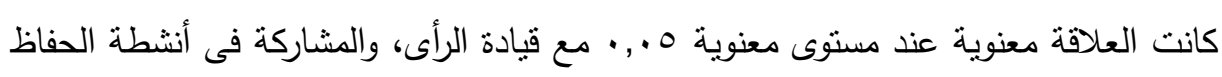

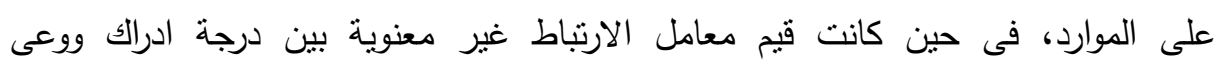

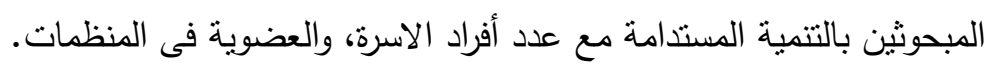

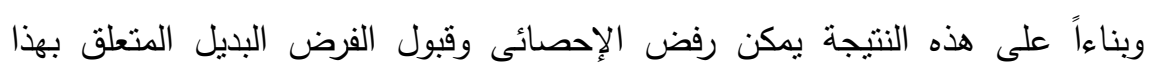

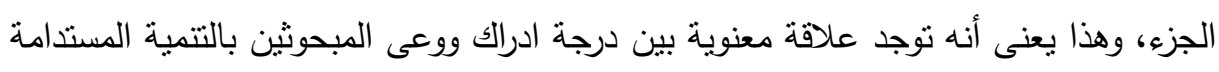

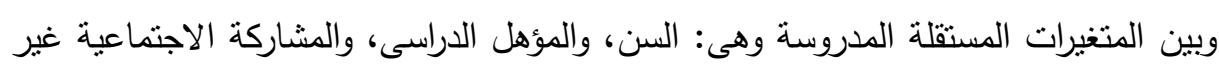

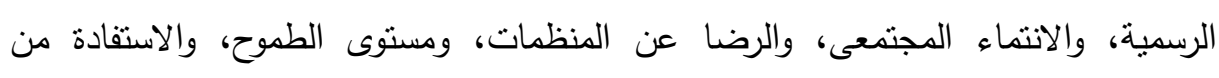

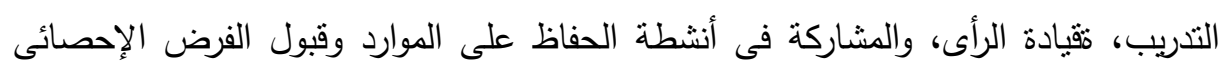

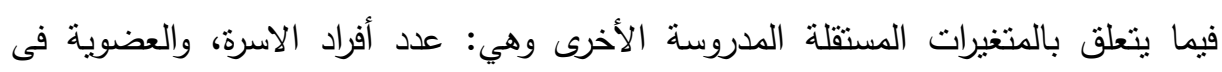
المنظمات. 
جدول رقم(ه): قيم معاملات الارتباط بين درجة ادراك ووعى المبحوثين بالتتمية المستدامة وبين المتغيرات المستقلة المدروسة

\begin{tabular}{|c|c|c|c|c|}
\hline القرضم & الالاتحراف & الحستوسطي & قالارتباط معامل & المتغيرات البحثية \\
\hline 1 & $9, V Y$ & $\sum \mu, 0$ & (***, I IV & السن \\
\hline $\bar{r}$ & $r, r q$ & $11 \%, 9$ & $* *, 19 \varepsilon$ & المؤهل الدراسي \\
\hline r & T,Yq & $\mathrm{V}, 1$ & $\cdot, 1 \mathrm{O}_{0}$ & عدد أفراد الاسرة \\
\hline$\varepsilon$ & $\Gamma, \wedge \varepsilon$ & $\Lambda, O \mathrm{~V}$ & $* *, 171$ & الانفتاح الثقافي \\
\hline 0 & $1, \mu \nu$ & $\Gamma, \Gamma V$ & $\cdot, 1 \cdot r$ & العضوية في المنظمات \\
\hline 7 & $\varepsilon, 1 \wedge$ & $1 \%, Y T$ & $* *, Y \leqslant 1$ & المشاركة الاجتماعية غير الرسمية \\
\hline $\bar{V}$ & $\Gamma, \xi \wedge$ & $1 \cdot, 17$ & $*, 1 \leq 0$ & ق ق قيادة الرأى \\
\hline$\Lambda$ & $\varepsilon, \Gamma Y$ & $1 \cdot, 9$ & $*, 1) \div \varepsilon$ & المشاركة في أنثطة الحفاظ على الموارد \\
\hline 9 & 0,71 & $10, \Sigma Y$ & $* *, 1 \wedge 0$ & الانتماء المجتمعي \\
\hline 1 . & $r, 0$ & $\Lambda, \vee q$ & $* *, Y Y \cdot$ & الرضا عن المنظمات المحلية \\
\hline 11 & $r, 77$ & $\Lambda, \cdot r$ & $* *, 1 \wedge \varepsilon$ & مستوى الطموح \\
\hline IT & $r, q$ & $\varepsilon, Y \varepsilon$ & $* *, 1 \vee 7$ & الاستفادة من التندريب \\
\hline
\end{tabular}

\section{ه - المشكلات التى تواجه المبحوثين بمنطقة الدراسة ومقترحاتهم لحلها :}

أ- المشكلات التى تواجه المبحوثين بمنطقة الاراسة: أظهرت النتائج المبينة بالجدول رقم أن هناك اثثى عشرة مشكلة تواجه المبحوثين بمنطقة الدراسة وكانت أكثر المشكلات

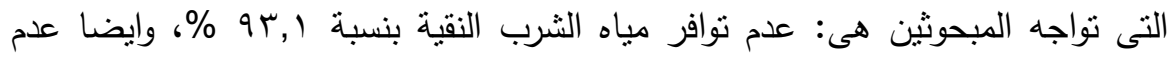

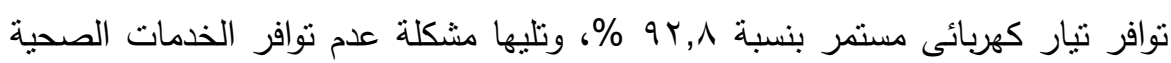

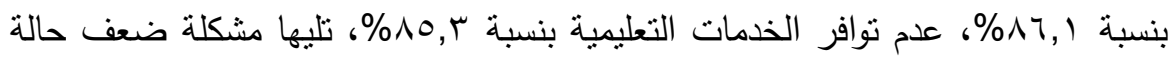
الطرق والمواصلات بنسبة r,^^\%، بالاضافة لضعف المعلومات الارشادية الزراعية

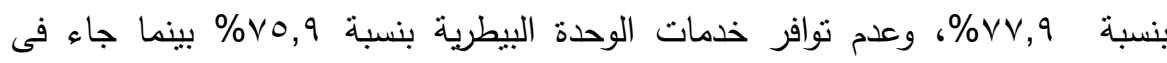

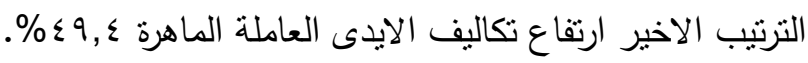


جدول رقم(آ): المشكلات التى تواجه المبحوثين بنطقة الدراسة

\begin{tabular}{|c|c|c|c|c|}
\hline الترتيب & $\%$ & عدد & المشكلات & ? \\
\hline 1 & 94,1 & rYA & عدم توافر مياه الثرب النقية & 1 \\
\hline $\bar{r}$ & $9 Y, \Lambda$ & TrO & عدم توافر تيار كهربائي مستمر & r \\
\hline r & $\Lambda 7,1$ & YII & عدم توافر الخدمات الصحية & $\mu$ \\
\hline$\varepsilon$ & $\Lambda 0, \Gamma$ & r. 9 & عدم توافر الخدمات التعليمية & $\varepsilon$ \\
\hline 0 & $\Delta r, r$ & $r \cdot \varepsilon$ & ضعف حالة الطرق والمواصلات & 0 \\
\hline$\Lambda$ & $V \mu, 1$ & 189 & ضعف نشاط الجمعيات التعاونية الزراعية & 7 \\
\hline $\mathrm{V}$ & $V 0,9$ & $1 / 7$ & عدم توافر خدمات الوحدة البيطرية & $\mathrm{V}$ \\
\hline 7 & $\nabla V, q$ & 191 & ضعف المعلومات الارشادية الزراعية & $\Lambda$ \\
\hline 1. & $7 \varepsilon, \Lambda$ & 109 & عدم وجود مراكز تسويق للحاصلات الزراعية & 9 \\
\hline 11 & $0 \wedge, \varepsilon$ & $1 \leqslant \Gamma$ & ارتفاع اسعار الاعلاف المركزة & 1. \\
\hline 9 & $\overline{v 1,1}$ & $T V \varepsilon$ & وجود مراكز صبانة المعدات والالات & 11 \\
\hline$T$ & $\sum q, \varepsilon$ & TY & ارتفاع تكاليف الايدى العاملة الماهرة & TY \\
\hline
\end{tabular}

ب- مقترحات المبحوثين لحل المشكلات التى تواجههم: أظهرت النتائج المبينة بالجدول رقم

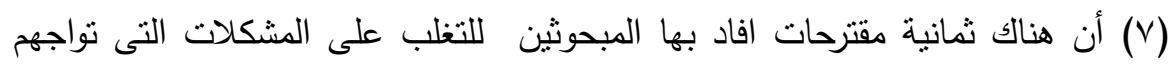
بمنطقة الدراسة وهى مرنبة نرتيبا تتازليا كما ذكرها المبحوثين على النحو التالى: ضرورة

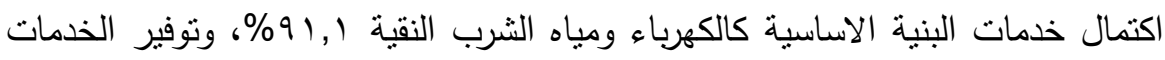

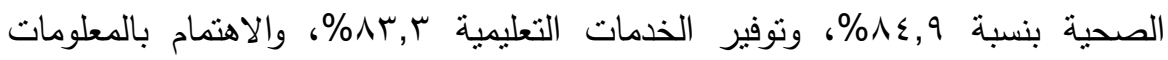

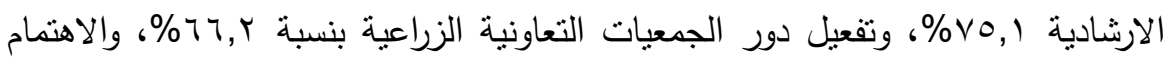
بتوفير مراكز صيانة متخصصة ه,؟؟ \% \%، بينما جاء فى الترتيب الاخير تدريب العمالة

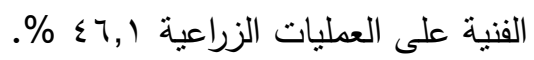


جدول رقم(V): مقترحات المبحوثين للتغلب على المشكلات التى نواجهمه بمنطقة الدراسة

\begin{tabular}{|c|c|c|c|}
\hline$\%$ & عدد & المقترحات & م \\
\hline 91,1 & TYM & ضرورة اكتمال خدمات البنية الاساسية كالكهرباء ومياه الثرب النقية & 1 \\
\hline$\Lambda \mu, r$ & $r \cdot \varepsilon$ & توفير الخدمات التعليمية & r \\
\hline$\Lambda \varepsilon, 9$ & $r \cdot \Lambda$ & ضرورة نوفير الخدمات الصحية & r \\
\hline 77,0 & 174 & تفعيل دور الجمعيات التعاونية الزراعية & $\varepsilon$ \\
\hline $7 \varepsilon, 0$ & 101 & توفير مراكز صيانة متخصصة للمعدات والالات & 0 \\
\hline$V \cdot, r$ & IVY & ضرورة توفير الخدمات والادوية البيطرية للمبي الحيوانات البيطرية & 7 \\
\hline$v 0,1$ & $1 \wedge \varepsilon$ & الاهتمام بتوفير المعلومات الارشادية الزراعية & $\mathrm{V}$ \\
\hline $0 V, 0$ & $1 \leqslant 1$ & توفير مستلزمات الانتاج & $\Lambda$ \\
\hline$\sum 7,1$ & $11 \pi$ & تدريب العمالة الفنية على العمليات الزراعية & 9 \\
\hline
\end{tabular}

المصدر: نتائج التحليل الاحصائي

\section{المتوسياتش}

• فى ضوء ما أوضحتة نتائج الدراسة من انخفاض وعى المبحوثين بالتتمية المستدامة لذلك

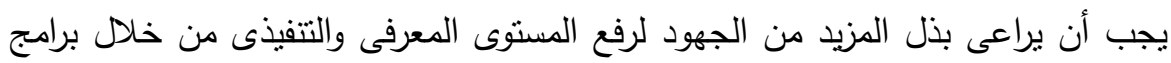

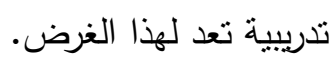

• ينبغي أن تقوم الجهات المسئولة بنقل المشكلات الى جهات البحث العلىى لايجاد الحلول بما يتفق مع طبيعة المنطقة. • الاهتمام بالثقافة ونشر الوعي بتدعيم المكتبات والمعارض وتتشيع الفنون الثعبية والمحافظة على النتراث الاجتماعي والهوية السيناوية.

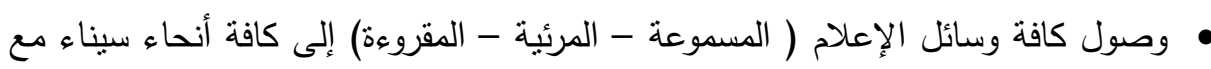
وجود قنوات نليفزيونية وإذاعة خاصة لكل منطقة لمخاطبة مواطني هذه المناطق طبقاً لعاداتهم وتقاليدهم وطموحاتهم.

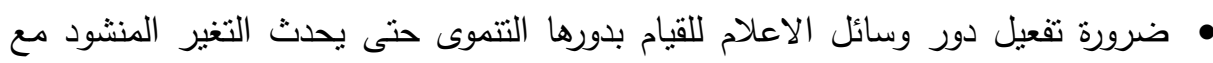
التركيز على أثنكال التقديم الحوارية والتحليلات السياسية. 


\section{المرامئ2}

أحمد عبد الموجود الشناوي: بعنوان (بدو سيناء، إثكالية الهوية والاتنماء) أحوال مصرية العدد

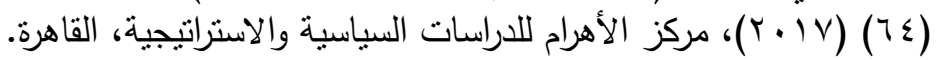

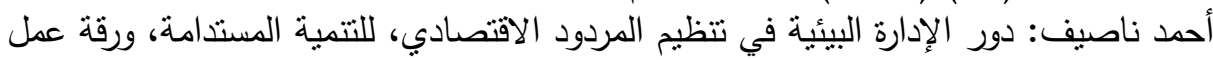

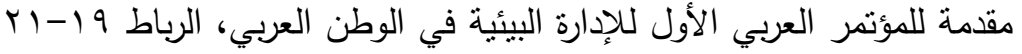

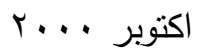

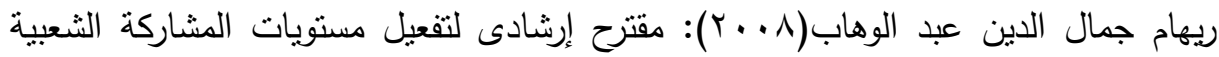

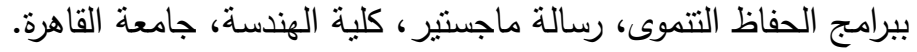

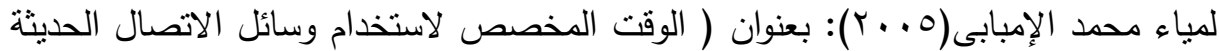

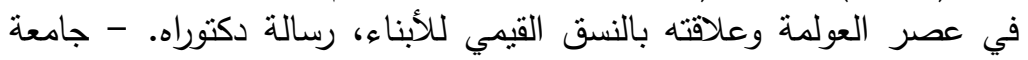

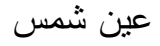

ليلى حسين السيد، حسن عماد مكاوي(1 . . ب): الاتصال ونظرياته المعاصرة، الدار المصرية اللبنانية للنشر

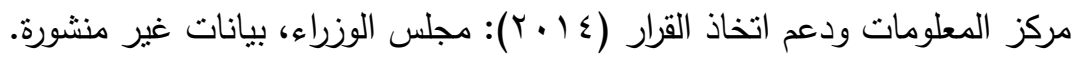

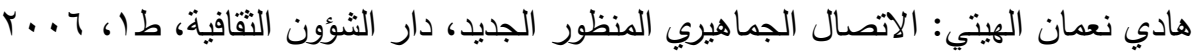

Faculty of Built(2001): " Towards sustainability in TH Built Environment " A.Shanableh. Environmental and Engineering, Queen island University of Technology, pp.40-41.

http://www. saudigs. org/forums/showthread. php? $\mathrm{p}=6011$ Accessed on 2010

Jonathan M. Harris(2000): Basic principles of sustainable development, working paper, Global Development and Environment, Tufts University. USA..

Sim, Sunhui(2010): A geospatial approach to measuring and modeling the impact of urban growth on ecosystem "Orland case study", ph. D. dissertation ,The Florida states university, United States 


\title{
THE MEDIA'S ROLE TO CONFRONT SOCIAL AND ECONOMIC PROBLEM IN NORTH SINAI GOVERNORATE
}

\author{
Soliman, Nahla, E. M. ${ }^{(1)}$; Ibrahim, M. M..$^{(2)}$ and Hussein, M. A. ${ }^{(3)}$ \\ 1) Institute of Environmental Studies \& Research, Ain Shams \\ University 2) Institute of Childhood Studies, Ain Shames University \\ 3) Faculty of Arts, University of Damietta
}

\begin{abstract}
ABESTRACT
The goal of this research is to define the most important sources of information related to the people subject of this research in the studied region. Also to determine the degree of awareness of those people relevant to the sustainable development and also to define the media's role in handling the general cases and problems encountered by the people subject to this research in the studied region and to recognize their suggestions for the solutions. And finally to specify the nature of the relation between the changes of this independent studied and the awareness level of people subject of this research with the sustainable development.

The data relevant to this research were gathered through personal interview and by the use of a questionnaire specially prepared to realize the study goals, and has been systematically applied on chosen random sample of 245 persons representing $5 \%$ of the inhabitants of North Sinai governorate. In order to display data a repetition table system was used to determine the percentage, the calculated average, the standard deviation, and the average degree and Liberson simple related coefficient. The most important results indicated low level of awareness of the studied persons with the sustainable development, about two third of the studied sample of people $(65.1 \%)$ were knowledgeable, the first third $(39.2 \%)$ of the studied sample have low level of knowledgeable and the second third $(35,9 \%)$ have medium 306

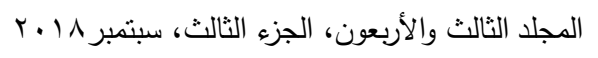


level of knowledgeable. The most important resources from which researchers get their information were as follows in a descending order; the first source is the internet by an average of 2.47 , the second from satellite television channels by an average of 2, 52, the third from local television channels, the fourth by radio broadcasting by an average of 1.67 and the last source is from technical news by an average of 0.53 . There is a positive moral relation between the awareness level of the studied persons with the sustainable development and the studied independent changes like age, level of education, the non official social sharing, loyalty to the community, level of ambitious and the benefits gained from training by an average degree of 0.01 , while there is moral relation at an average moral degree of 0.05 related to opinion command and sharing in resources preservation programs.

The value of linkage coefficient was not moral in relation to acknowledgement degree and awareness level of the sustainable development among the studied persons with family number and their membership in various organizations. 